\title{
Damage costs of climate change through intensification of tropical cyclone activities: an application of FUND
}

\author{
Daiju Narita $^{1, *}$, Richard S. J. Tol ${ }^{2,3,4}$, David Anthoff ${ }^{2}$ \\ ${ }^{1}$ Kiel Institute for the World Economy, Düsternbrooker Weg 120, Kiel 24105, Germany \\ ${ }^{2}$ Economic and Social Research Institute, Whitaker Square, Sir John Rogerson's Quay, Dublin 2, Ireland \\ ${ }^{3}$ Institute for Environmental Studies and Department of Spatial Economics, Vrije Universiteit, De Boelelaan 1081, \\ Amsterdam, The Netherlands \\ ${ }^{4}$ Department of Engineering and Public Policy, Carnegie Mellon University, Baker Hall 129, Pittsburgh, Pennsylvania 15213, USA
}

\begin{abstract}
Climate change may intensify tropical cyclone activities and amplify their negative economic effects. We simulated the direct economic impact of tropical cyclones enhanced by climate change with the integrated assessment model Climate Framework for Uncertainty, Negotiation and Distribution (FUND), Version 3.4. The results show that in the basic case (parameter levels based on intermediate estimates), the direct economic damage caused by tropical cyclones ascribed to the effect of climate change would amount to US\$19 billion globally in the year 2100 (almost the same level as the baseline, i.e. current global damage of tropical cyclones), while the ratio to world gross domestic product (GDP) would be $0.006 \%$. The USA and China account for much of the absolute damage, whereas Small Island States incur the largest damage if evaluated as the proportion of GDP. Model results were sensitive to the choice of baseline and of the wind-speed elasticity of storm damage.
\end{abstract}

KEY WORDS: Climate change · Tropical storms · Economic impact

\section{INTRODUCTION}

It is a well-accepted fact that tropical cyclones (hurricanes, typhoons) sometimes have large economic effects. Hurricane Katrina, which hit the Caribbean and the southern United States in August 2005 and incurred a direct economic loss estimated to be over US\$125 billion (Munich Re 2006a), is a vivid example of how substantial the economic impacts of tropical cyclones can be. Worryingly, tropical cyclone activity may be enhanced with the rise of global atmospheric temperatures, with corresponding negative economic effects in the future. Although storm activities vary greatly from year to year, and their general trends are thus not easily discernable, scientific evidence increasingly provides support for this claim. For example, the Intergovernmental Panel on Climate Change (IPCC)'s
Fourth Assessment Report (IPCC 2007) recognizes substantial increases in the intensity and duration of tropical storms or hurricanes since the 1970 s . It also estimates that it is likely that tropical cyclones will become severe and have greater wind speeds and more intense precipitation, and that such enhancement of cyclone activities could have significant impacts on human activities, causing for example crop failures, death and injuries, and flood damage resulting in loss of property.

The basic physical characteristics of tropical cyclones are fairly well identified (e.g. Emanuel 2003, 2005), and it is in fact logical to infer that global climate change should increase damage inflicted by tropical cyclones. Tropical cyclones are defined as cyclones that originate over tropical oceans (those with maximum winds over $33 \mathrm{~m} \mathrm{~s}^{-1}$ are called hurricanes in the western North Atlantic and eastern North Pacific 
regions, and typhoons in the western North Pacific), while they may move out of the tropics after their genesis. The source of energy for tropical cyclones is heat transfer from the ocean, which induces upward motion of air in the lower atmosphere, causes convection, and eventually forms self-sustaining patterns of winds and rainfall. Tropical cyclones generally develop only over seawater whose surface temperature is greater than $26^{\circ} \mathrm{C}$. The mechanism of their formation suggests that the rise in sea surface temperature due to enhanced greenhouse effect should lead to some amplification of tropical cyclone activities, and scientists have reached a consensus on this general point.

On the other hand, details on the effects of climatology on tropical cyclones are very complex and remain uncertain to a large extent because of the non-linearity of the cyclone generation mechanism, the interconnectedness of cyclones to large-scale oscillations of global atmospheric circulations, and also limitations on the availability of historical records of observations. For example, the formation of tropical cyclones is known to be influenced by the vertical thermodynamic properties of the atmosphere, which could be a diminishing factor of cyclone activities in the presence of anthropogenic greenhouse warming (e.g. Vecchi \& Soden 2007). Meanwhile, the mechanism linking tropical cyclone activities and sea surface temperatures is not well clarified except for some research findings on the North Atlantic region (e.g. WMO 2006), although there is indeed some consensus on the global tendency of ocean warming and cyclone intensification, as evidenced by the World Meteorological Organization's statement that '[m]odel studies and theory project a 3 to $5 \%$ increase in wind-speed per degree Celsius increase of tropical sea surface temperatures' (WMO 2006). It should be noted, however, that the frequency, not wind-speeds, of tropical cyclones could be unchanged or even reduced with enhanced greenhouse effects (e.g. Emanuel et al. 2008, Knutson et al. 2008).

Economic assessments of damage due to tropical cyclones have already drawn great interest from various groups of people and organizations, notably of the (re)insurance industry (e.g. Munich Re 2006b, Swiss Re 2006). ${ }^{1}$ Several estimates of the enhanced economic effects (due to climate change) of tropical cyclones have also been presented (Cline 1992, Fankhauser 1995, Tol 1995, Downing et al. 1996, Nordhaus 2006, Pielke 2007).

In the field of development economics, there has been a debate recently about how geographical characteristics such as climatic conditions influence re-

\footnotetext{
1 Jagger et al. (2008) discuss forecasting methodology of
} insured hurricane losses affecting the USA gional performances of economic growth (e.g. Gallup et al. 2000, Acemoglu et al. 2001, Easterly \& Levine 2003), and some useful studies on the economics of natural disasters are found in this set of studies (e.g. Kahn 2005, Toya \& Skidmore 2007). Their primary question is whether the burdens of frequent natural disasters can inhibit economic growth, or whether wealth can mitigate loss from natural disasters. For example, Toya \& Skidmore (2007) conducted a crosscountry analysis to estimate the relationships between measures of social or economic development and the effects of natural disaster and identified an inverse relationship between income and natural disaster losses.

Most economic studies estimating the impacts of climate change have still paid little attention to extreme events such as hurricanes. For example, major recent econometric studies on the impacts of climate change on agriculture (e.g. Schlenker et al. 2005, Deschênes \& Greenstone 2007) examine yield responses to baseline temperature increases and do not explicitly take into account the potential significance of extreme weather events in productivity loss, while some agronomic studies attempted to address this question with regard to crop growth, but without any monetary assessment (e.g. Rosenzweig et al. 2002, Porter \& Semenov 2005).

The fact that cyclone damage has a 2-way interrelationship with long-term growth (i.e. relative cyclone impacts decrease with economic growth, but cyclone damage reduces economic growth) suggests that the impact assessment of tropical cyclones and climate change would make a suitable topic for climateeconomy integrated assessment models. However, major recent studies of integrated assessment models such as Mendelsohn et al. (2000) and Nordhaus \& Boyer (2000) do not explicitly incorporate the effects of tropical cyclones in their climate-economy models, presumably because they regard the scientific evidence as not yet strong enough.

The purpose of this study is to analyze the long-term economic effects of tropical cyclones in the face of climate change, computed by the integrated assessment model Climate Framework for Uncertainty, Negotiation and Distribution (FUND) 3.4. Earlier versions of FUND already had a component on tropical cyclone damage, and some studies using FUND have presented results including the effects of hurricanes (e.g. Tol 1999), but the model's tropical cyclone component was not specifically evaluated before. In fact, tropical cyclones were omitted by Tol (2002a) and in all versions of FUND based on that paper. In the following, brief descriptions of FUND and of our approach to model the damage of tropical cyclones are presented in Section 2. Section 3 shows the results. Section 4 concludes. 


\section{METHODOLOGY: ESTIMATION OF TROPICAL CYCLONE IMPACTS WITH FUND}

\subsection{The FUND model}

We used Version 3.4 of FUND for our analysis of climate change impacts attributable to enhancement of tropical cyclone activities. Version 3.4 of FUND has the same basic structure as that of Version 1.6, which was described and applied by Tol (1999, 2001, 2002c). Except for the tropical cyclone component which will be discussed in this paper, the impact module of the model was outlined and assessed by Tol $(2002 a, b)$. The latest publication using the FUND platform is that of Anthoff et al. (2009). The source code, a complete description of the model and all papers that apply FUND (including papers on individual model components and discussions of input sources) can be found at www.fund-model.org. Below, we outline the overall model and provide details on the parts of the model that are used in the current paper.
Essentially, FUND is a model that calculates damage caused by climate change for 16 regions of the world listed in Table 1 by making use of exogenous scenarios of socioeconomic variables. The scenarios comprise projected temporal profiles of population growth, economic growth, autonomous energy efficiency improvements and carbon efficiency improvements (decarbonization), emissions of carbon dioxide from land use change, and emissions of methane and of nitrous oxide. Carbon dioxide emissions from fossil fuel combustion are computed endogenously on the basis of the Kaya identity. The calculated impacts of climate change perturb the default paths of population and economic outputs corresponding to the exogenous scenarios. The model runs from the years 1950 to 3000 in time steps of a year, though the outputs for the 1950 to 2000 period is only used for calibration, and the years beyond 2100 are used for approximating the social cost of carbon under low discount rates, a matter that does not concern us in this paper. The scenarios up to the year 2100 are based on the EMF 14 Standardized Sce-

Table 1. Regions considered in the Climate Framework for Uncertainty, Negotiation and Distribution (FUND)

\begin{tabular}{|c|c|c|}
\hline Acronym & Name & Countries \\
\hline USA & USA & United States of America \\
\hline CAN & Canada & Canada \\
\hline WEU & Western Europe & $\begin{array}{l}\text { Andorra, Austria, Belgium, Cyprus, Denmark, Finland, France, Germany, Greece, } \\
\text { Iceland, Ireland, Italy, Liechtenstein, Luxembourg, Malta, Monaco, Netherlands, } \\
\text { Norway, Portugal, San Marino, Spain, Sweden, Switzerland, United Kingdom }\end{array}$ \\
\hline JPK & Japan and South Korea & Japan, South Korea \\
\hline ANZ & Australia and New Zealand & Australia, New Zealand \\
\hline EEU & Central and Eastern Europe & $\begin{array}{l}\text { Albania, Bosnia and Herzegovina, Bulgaria, Croatia, Czech Republic, Hungary, } \\
\text { FYR Macedonia, Poland, Romania, Slovakia, Slovenia, Yugoslavia }\end{array}$ \\
\hline FSU & Former Soviet Union & $\begin{array}{l}\text { Armenia, Azerbaijan, Belarus, Estonia, Georgia, Kazakhstan, Kyrgyzstan, Latvia, } \\
\text { Lithuania, Moldova, Russia, Tajikistan, Turkmenistan, Ukraine, Uzbekistan }\end{array}$ \\
\hline MDE & Middle East & $\begin{array}{l}\text { Bahrain, Iran, Iraq, Israel, Jordan, Kuwait, Lebanon, Oman, Qatar, Saudi Arabia, } \\
\text { Syria, Turkey, United Arab Emirates, West Bank and Gaza, Yemen }\end{array}$ \\
\hline CAM & Central America & Belize, Costa Rica, El Salvador, Guatemala, Honduras, Mexico, Nicaragua, Panama \\
\hline SAM & South America & $\begin{array}{l}\text { Argentina, Bolivia, Brazil, Chile, Colombia, Ecuador, French Guiana, Guyana, } \\
\text { Paraguay, Peru, Suriname, Uruguay, Venezuela }\end{array}$ \\
\hline SAS & South Asia & Afghanistan, Bangladesh, Bhutan, India, Nepal, Pakistan, Sri Lanka \\
\hline SEA & Southeast Asia & $\begin{array}{l}\text { Brunei, Cambodia, East Timor, Indonesia, Laos, Malaysia, Myanmar, Papua New } \\
\text { Guinea, Philippines, Singapore, Taiwan, Thailand, Vietnam }\end{array}$ \\
\hline $\mathrm{CHI}$ & China plus & China, Hong Kong, North Korea, Macau, Mongolia \\
\hline NAF & North Africa & Algeria, Egypt, Libya, Morocco, Tunisia, Western Sahara \\
\hline SSA & Sub-Saharan Africa & $\begin{array}{l}\text { Angola, Benin, Botswana, Burkina Faso, Burundi, Cameroon, Cape Verde, Central } \\
\text { African Republic, Chad, Congo-Brazzaville, Congo-Kinshasa, Cote d'Ivoire, Djibouti, } \\
\text { Equatorial Guinea, Eritrea, Ethiopia, Gabon, Gambia, Ghana, Guinea, Guinea- } \\
\text { Bissau, Kenya, Lesotho, Liberia, Madagascar, Malawi, Mauritania, Mozambique, } \\
\text { Namibia, Niger, Nigeria, Rwanda, Senegal, Sierra Leone, Somalia, South Africa, } \\
\text { Sudan, Swaziland, Tanzania, Togo, Uganda, Zambia, Zimbabwe }\end{array}$ \\
\hline SIS & Small Island States & $\begin{array}{l}\text { Antigua and Barbuda, Aruba, Bahamas, Barbados, Bermuda, Comoros, Cuba, } \\
\text { Dominica, Dominican Republic, Fiji, French Polynesia, Grenada, Guadeloupe, Haiti, } \\
\text { Jamaica, Kiribati, Maldives, Marshall Islands, Martinique, Mauritius, Micronesia, } \\
\text { Nauru, Netherlands Antilles, New Caledonia, Palau, Puerto Rico, Reunion, Samoa, } \\
\text { Sao Tome and Principe, Seychelles, Solomon Islands, St Kitts and Nevis, St Lucia, St } \\
\text { Vincent and Grenadines, Tonga, Trinidad and Tobago, Tuvalu, Vanuatu, Virgin Islands }\end{array}$ \\
\hline
\end{tabular}


nario $(\mathrm{EMF}=$ Energy Modeling Forum), which lies somewhere in between IPCC Scenarios IS92a ('business as usual') and IS92f ('high population growth') (Leggett et al. 1992). $\underline{\underline{2}}$ The radiative forcing of carbon dioxide and other greenhouse gases used by FUND is determined based on Shine et al. (1990). The global mean temperature is governed by a geometric buildup to its equilibrium (determined by the radiative forcing) with a half-life of $50 \mathrm{yr}$. In the base case, the global mean temperature increases by $2.5^{\circ} \mathrm{C}$ in equilibrium for a doubling of carbon dioxide equivalents. Regional temperature increases, which are the primary determinant of regional climate change damage (except for tropical cyclones, as discussed below), are calculated from the global mean temperature change multiplied by a regional fixed factor, which equals the unweighted average of the spatial patterns of 14 General Circulation Models (GCMs) (Mendelsohn et al. 2000).

As described by Tol (2002a), the model considers the damage caused by climate change (apart from tropical cyclones) for the following categories: agriculture, forestry, water resources, sea level rise, energy consumption, unmanaged ecosystems, and human health (diarrhea, vector-borne diseases, and cardiovascular and respiratory disorders). In our version of FUND, tropical cyclones are treated as a separate category, rather than as a factor elevating damage levels in the existing categories (e.g. crop damage from enhanced floods). Impacts of climate change can be attributed to either the rate of temperature change (benchmarked at $0.04^{\circ} \mathrm{C}$ per year) or the level of temperature change (benchmarked at $1.0^{\circ} \mathrm{C}$ ). Negative economic effects associated with the rate of temperature change gradually diminish because of adaptation.

FUND also has macroeconomic and policy components. Reduced economic output due to damage caused by climate change is translated into lower investment (with exogenous saving rates) and consequently slower growth rates. By using additional variables representing emission reductions, FUND can be operated as an assessment tool for long-run climate policy. In this paper, however, we do not discuss emission reduction policy and thus do not use this policyassessment function of the model.

\subsection{Tropical cyclones}

We calculated the economic damage caused by climate change through tropical cyclone activities with

$\underline{2}$ The FUND scenario is as arbitrary as any other scenario used for climate change analysis. The results below do not suggest that the estimates are particularly sensitive to the details of the assumed scenario
Table 2. Baseline impact of tropical cyclones on property (direct economic damage) and mortality (based on 1986 to 2005 averages from the Center for Research on the Epidemiology of Disasters Emergency Events Database, CRED EM-DAT). GDP: gross domestic product; $\alpha_{r}$ : factor determining the baseline level of economic damage from cyclones for region $r_{\text {; }}$ $\beta_{r}$ : regional baseline level of mortality from tropical cyclones. Region acronyms as listed in Table 1

\begin{tabular}{|lcccc|}
\hline Region & $\begin{array}{c}\text { Direct economic damage } \\
\text { Loss in } \\
\text { billion } \\
\text { US\$ }\end{array}$ & $\begin{array}{c}\alpha_{r} \\
\text { (\% of GDP) }\end{array}$ & $\begin{array}{c}\text { Mortality } \\
\text { No. of } \\
\text { casualties }\end{array}$ & $\begin{array}{c}\beta_{r} \\
\text { (per million } \\
\text { people) }\end{array}$ \\
\hline USA & 13 & 0.15 & 115 & 0.39 \\
CAN & $5.6 \times 10^{-3}$ & $7.4 \times 10^{4}$ & 0.15 & $4.9 \times 10^{-3}$ \\
WEU & $1.5 \times 10^{-4}$ & $1.7 \times 10^{-6}$ & 0.80 & $2.1 \times 10^{-3}$ \\
JPK & 2.0 & 0.033 & 92 & 0.54 \\
ANZ & 0.043 & 0.010 & 1.4 & 0.067 \\
EEU & 0 & 0 & 0 & 0 \\
FSU & $7.9 \times 10^{-3}$ & $1.7 \times 10^{-3}$ & 2.1 & $7.09 \times 10^{-3}$ \\
MDE & 0 & 0 & 0.35 & $1.4^{-3}$ \\
CAM & 0.71 & 0.18 & 1090 & 8.2 \\
SAM & 0.020 & $1.3 \times 10^{-3}$ & 7.3 & 0.024 \\
SAS & 0.44 & 0.094 & 7985 & 6.9 \\
SEA & 0.36 & 0.041 & 1177 & 2.4 \\
CHI & 1.9 & 0.20 & 348 & 0.29 \\
NAF & 0 & 0 & 0 & 0 \\
SSA & 0.021 & $5.9 \times 10^{-3}$ & 87 & 0.14 \\
SIS & 0.83 & 0.57 & 213 & 4.9 \\
& & & & \\
\hline
\end{tabular}

the following function:

$$
\frac{T D_{t, r}}{Y_{t, r}}=\alpha_{r}\left(\frac{Y_{t, r}}{Y_{1990, r}}\right)^{\varepsilon}\left[\left(1+\delta \cdot \theta_{r} T_{t, \text { global }}\right)^{\gamma}-1\right]
$$

Note that the equation represents the effect of a deviation of tropical cyclones from its baseline (i.e. not the total level of cyclone damage). $T D_{t, r}$ and $Y_{t, r}$ are damage due to tropical cyclones (increase relative to pre-industrial) and gross domestic product (GDP), respectively, in region $r$ and time $t . \alpha_{r}$ is the factor determining the baseline level of cyclone damage for region $r$ (see Table 2). The data for cyclone damage are drawn from the Emergency Events Database (EM-DAT: www.emdat.be/) by the WHO Collaborating Center for Research on the Epidemiology of Disasters (CRED). The CRED EM-DAT is an international initiative which assembles and organizes the data of natural disaster damage collected by various institutions worldwide (i.e. UN organizations, governments, NGOs, universities, private firms, and the press). The database contains basic data on the occurrence and the effects of more than 17000 disasters in the world from 1900 to the present (Scheuren et al. 2008). Although the dataset has the weakness that its economic damage data are listed on a reported basis from different institutions and lacks con- 


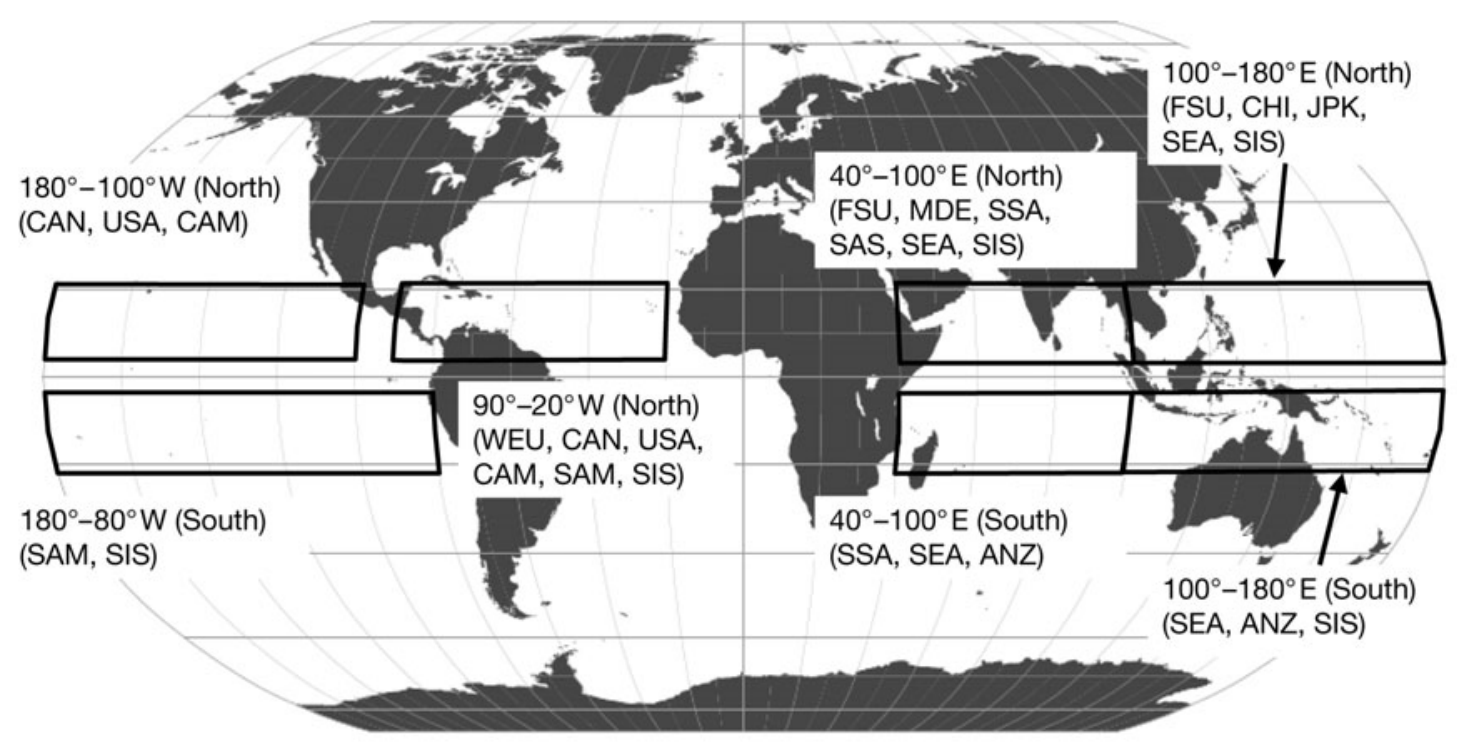

Fig. 1. Tropical areas corresponding to the world regions (i.e. areas considered to be the origins of tropical cyclones which move to the respective regions). Upper and lower bounds of the bands are $25^{\circ}$ and $5^{\circ} \mathrm{N}$ in the Northern Hemisphere and $5^{\circ}$ and $25^{\circ} \mathrm{S}$ in the Southern Hemisphere. Region acronyms as listed in Table 1

sistency, $\underline{\underline{3}}$ it is the only comprehensive data-set in the public domain. The coefficient $\alpha_{r}$ is estimated by averaging storm damage in the dataset over the period 1986 to 2005. It should be noted that storm impacts vary greatly year to year, and the level of the coefficient is extremely sensitive to which period is chosen and averaged. We addressed this issue by conducting a set of sensitivity runs, which are discussed in the next section.

The component $\left(y_{t, r} / y_{1990, r}\right)^{\varepsilon}$ in Eq. (1) represents the effect of income level on vulnerability to storms, where $y$ is per capita income (in 1995 US\$ per year) in region $r$ at time $t$. Two factors are in play with regard to the relationship between affluence and damage caused by disaster: ${ }^{4}$ economic damage resulting from natural disasters may be magnified in richer economies because a unit amount of loss in capital leads to a bigger loss in income due to the high productivity of capital; on the other hand, wealthier countries can insulate themselves from damage caused by disaster by defensive expenditure or expensive but better infrastructure

$\underline{3}$ Toya \& Skidmore (2007) point out 3 additional factors which would reduce the reliability of economic estimates in the Emergency Events Database (EM-DAT). (1) The database only includes direct costs of disasters and omits indirect costs. (2) Governments of low-income countries have an incentive to overstate the damage of disasters in order to draw foreign assistance. (3) Data collection is a challenging issue in lowincome countries because the poor often lack access to established markets and insurance

${ }^{4}$ Tol \& Leek (1999) give detailed discussions on the causal link between income levels and damage caused by natural disasters which is resistant to disaster shocks. In Eq. (1), $\varepsilon$ is the income elasticity of storm damage set at -0.514 after Toya \& Skidmore (2007).

The relative annual level of cyclone damage increases with warming temperatures. The rise in tropical sea temperatures, which is part of the global climate change phenomenon, is a factor which increases the maximum wind speed of cyclones, and cyclones with greater wind speed cause greater damage. [(1+ $\left.\left.\delta \cdot \theta_{r} T_{t, \text { global }}\right)^{\gamma}-1\right]$ in Eq. (1) is the equation calculating this effect.

In the equation, $\delta$ is the parameter indicating how much wind speed increases per degree Celsius warming. The level of $\delta$ is set to be 0.04 , after the consensus statement by WMO (2006) $)^{\mathbf{5}} . T_{t, \text { global }}$ signifies the global average temperature increase since pre-industrial times (in ${ }^{\circ} \mathrm{C}$ ) at time $t$. The temperature levels are factored by regional coefficients $\theta_{r}$, representing the relative responsiveness of sea surface temperatures to the global temperature increases in tropical areas where cyclones affecting the respective regions originate (Fig. 1 shows which parts of the tropics correspond to respective regions). It should be noted that designated zones in Fig. 1 generally do not overlap with the actual land areas of the regions-for example, hurricanes affecting Western Europe (WEU) do not form in Europe but in the tropical Northern Atlantic, thus, the designated plot for WEU is located in the Atlantic, as seen on the map. The configurations shown in Fig. 1

${ }^{5}$ Exact quote of the statement: 'Model studies and theory project a $3-5 \%$ increase in wind-speed per degree Celsius increase of tropical sea surface temperatures.' 
are chosen to be consistent with actual track records of cyclones and reflect the following stylized facts about tropical cyclones (Emanuel 2003): by definition, tropical cyclones generate in the tropics $\left(23.4^{\circ} \mathrm{N}, 23.4^{\circ} \mathrm{S}\right)$; tropical cyclones are rarely formed around the equator below $5^{\circ}$ North and South; once formed, tropical cyclones move clockwise in the Northern Hemisphere and counterclockwise in the Southern Hemisphere and head poleward; almost no tropical cyclones are recorded in the Southern Atlantic. It should be also noted that the CRED EM-DAT data do not show any record of tropical cyclone damage in Central and Eastern Europe (EEU) and in North Africa (NAF), and thus the corresponding areas for those 2 regions are not indicated on the map. The coefficients $\theta_{r}$ are calculated as the ratios of the average sea surface temperature increases for the areas indicated in Fig. 1 to the global average surface temperature increases and are estimated by using the default $2.5 \times 2.5^{\circ}$ surface temperature outputs by MAGICC/SCENGEN 5.3 (whose model descriptions are found at www.cgd.ucar.edu/cas/wigley/ magicc/).

Finally, $\gamma$ is a parameter representing the relationship between the cyclone damage and the wind speed, which is in our case a function of the tropical sea surface temperature increase. It is conventional to assume that storm damage is proportional to the third power of wind speed (see, for example, Emanuel 2005). This assumption is based on the law of physics that the kinetic energy of wind affecting a unit area per unit of time is proportional to the cube of wind speed. This convention was recently challenged by Nordhaus (2006), who proposed a much greater value (namely 8) for describing storm damage based on his statistical analysis of US hurricane impacts. To justify his conclusion, he referred to the fact that the stress-fracture relationship of engineering objects or structures is highly non-linear - in other words, storm damage does not have to be proportional to the wind energy of storms. While his argument deserves attention, a high exponent is hardly a consensus yet. In our analysis, we use the exponent of 3 for standard runs and increase the level of $\gamma$ for a sensitivity run.

Similar to the rest of the impact module for FUND (see Tol 2002a for descriptions), the tropical cyclone component has a separate function estimating mortality in addition to that for economic damage:

$$
\frac{T M_{t, r}}{P_{t, r}}=\beta_{r}\left(\frac{y_{t, r}}{y_{1990, r}}\right)^{\eta}\left[\left(1+\delta \cdot \theta_{r} T_{t, \text { global }}\right)^{\gamma}-1\right]
$$

In Eq. (2), $T M_{t, r}$ and $P_{t, r}$ are the mortality due to tropical cyclones (increase relative to pre-industrial) and the population in region $r$ and time $t$, respectively. $\beta_{r}$ signifies the regional baseline level of mortality from tropical cyclones (based on the CRED EM-DAT data,

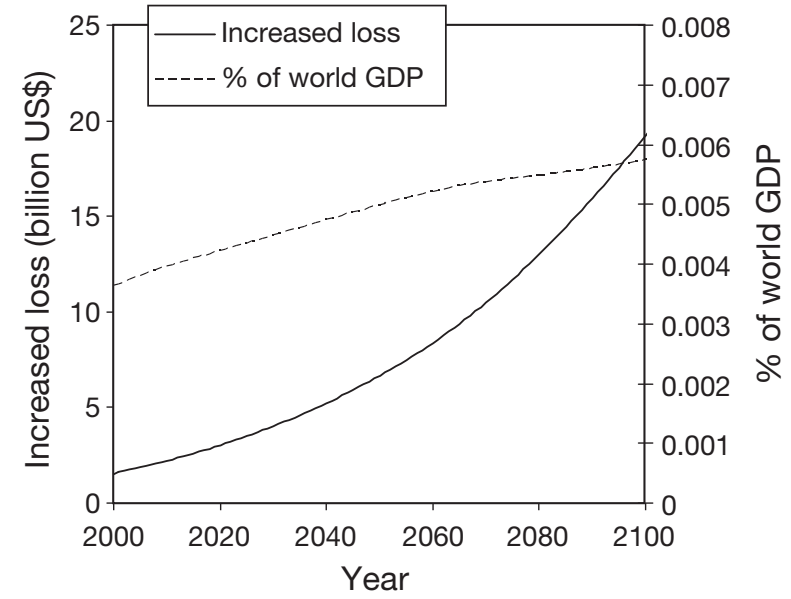

Fig. 2. Time trends of increased direct economic loss caused by tropical cyclones and its percent of the world gross domestic product (GDP)

see Table 2). $\eta$ is the income elasticity of storm damage on mortality and is set as -0.501 after Toya \& Skidmore (2007). The number of deaths computed by the equation is translated into loss of population. Mortality is also considered to be equivalent with some economic loss, which represents society's willingness to pay for saving human lives: as in the other impact categories in FUND, mortality due to tropical cyclones is valued at 200 times the per capita income of the specific region. This is set to be consistent with the discussion by Cline (1992), who drew on average annual wage data and estimates of the value of a statistical life.

\section{RESULTS}

Table 3 shows FUND's outputs on the change in economic damage and mortality due to tropical cyclones in the year 2100. The results shown reflect the increased damage of cyclones relative to the levels without climate change. Note that since we do not incorporate yearly randomness or periodic behaviour of storm activities in the model, it computes the baseline increase in storm damage exclusive of yearly fluctuations. As time trends of output are smooth (Fig. 2 shows time paths: see discussion below), the data on the table are not average values of multiple years but correspond to the single year of 2100 . In the base case, the climate-change-induced economic damage amounts to $\$ 19$ billion (1995 US\$ per year), which is roughly the same as the expected global total economic damage in

\footnotetext{
${ }^{6}$ Note that $\varepsilon$ and $\eta$ take different values since the effect of income level is not the same on tangible economic damage of disasters and on mortality
} 


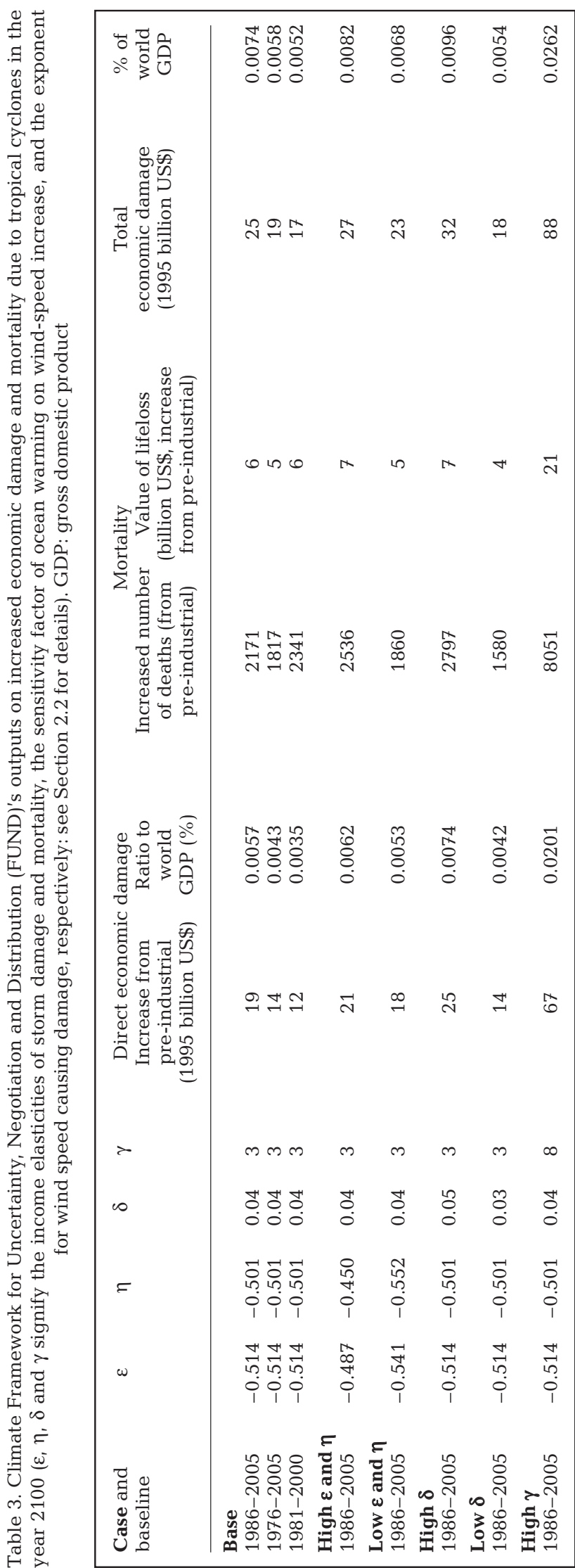

2005 (\$19 billion). The increase in global temperature $\left(3.2^{\circ} \mathrm{C}\right.$ since pre-industrial) is part of the reason for the large amount of the increased damage ${ }^{7}$ but the high level of loss is also due to the projected expanded size of the economy in 2100, which is almost 8 times the 2000 level. Fig. 2 shows the time trends of increased direct economic loss caused by tropical cyclones and its proportion of the world GDP for the base case (1986 to 2005 baseline). The graph shows a continuous increase of absolute cyclone damage, while the ratio of damage to GDP grows more slowly, and its rate of increase gradually diminishes. In 2100, the ratio reaches $0.0057 \%$ of the world GDP. While the increased income level reduces vulnerability to disasters (i.e. it reduces damage per unit amount of economic output), the rise in world GDP in absolute level results in a higher absolute level of damage. On the other hand, the share of damage to the world GDP is much more visibly influenced by the income effect on reduced vulnerability. Table 3 also shows that intensified storms would cause over 2000 additional deaths in the year 2100 in the base case. The monetized value of those fatalities amounts to $\$ 6$ billion, which is approximately $30 \%$ of the enhanced direct economic damage of $\$ 19$ billion. The value of lost life included, the increased damage due to enhanced cyclones corresponds to $0.0074 \%$ of the world GDP at 2100 .

Table 3 also shows the results of sensitivity runs. As noted before, cyclone damage is extremely variable year by year, and the choice of the baseline period has a large influence on the results. As an additional case, we extended the averaging period by $10 \mathrm{yr}$ (1976 to 2005). Also, we shifted the entire averaging period $5 \mathrm{yr}$ back from that of the base (first) case, to be in accordance with the claim that the year 2005 (when Katrina struck) was an anomalous year in the hurricane record (the opinion reviewed and discussed by Nordhaus 2006). As Table 3 shows, the direct economic damage is in fact smallest in the case of the 1981 to 2000 (without 2005) baseline (about $40 \%$ less in comparison to the economic damage-expresed as a ratio to world GDP - of the 1986-2005 case). Meanwhile, the difference among the different sets of baselines is less prominent with respect to mortality.

Fig. 3 shows the regional disaggregation of damage (direct economic loss) for cyclone-sensitive regions. The Katrina effect (unusually high hurricane damage in 2005) is in fact visible in the results for the USA, and the ratio of increased damage to GDP at 2100 falls in the range from 0.006 to $0.02 \%$, depending on the choice of baseline. With an absolute damage level over $\$ 2.5$ billion, the USA and China dominate with respect to global monetary cyclone damage as a consequence of

${ }^{7}(1+0.04 \times 1 \times 3.2)^{3}-1=0.435$ 

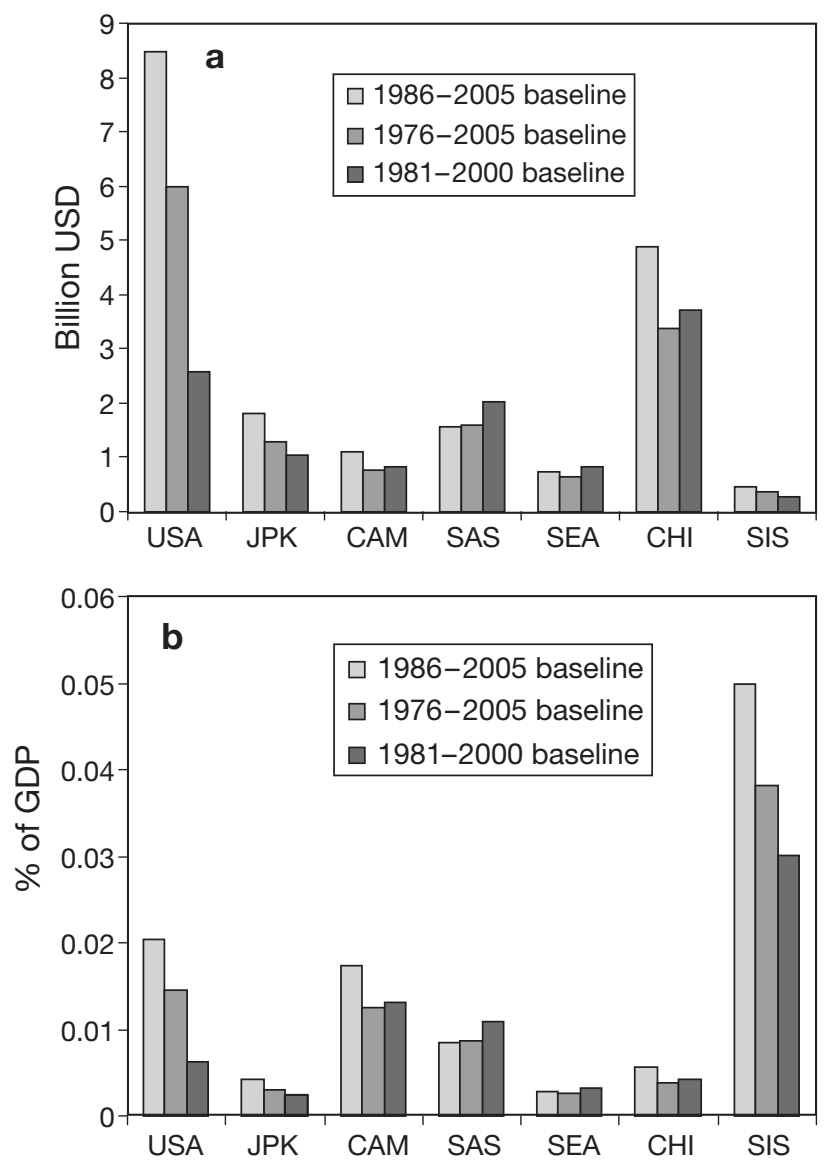

Fig. 3. (a) Increased direct economic loss and (b) its share of gross domestic product (GDP) in the year 2100 for selected regions (results for the 3 different baseline sets are shown). Region acronyms as listed in Table 1

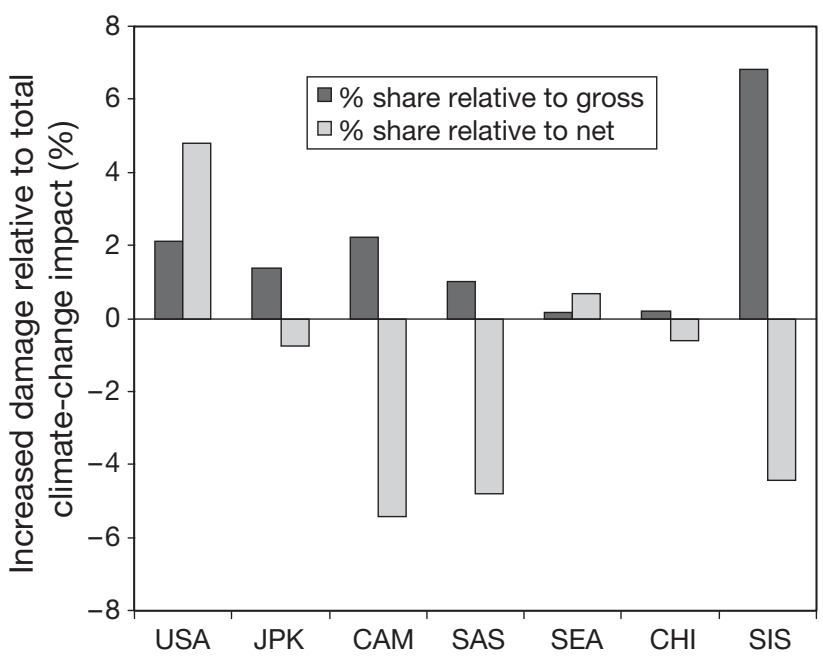

Fig. 4. Increased direct economic damage of tropical cyclones resulting from climate change as a fraction of the gross (i.e. only damage is considered) and net (both benefits and damage are summed) total costs of climate change for selected regions (in the year 2100 for the base case). Region acronyms as listed in Table 1 their large economic size combined with relatively high vulnerability to cyclones. However, Small Island States show the highest level of damage, amounting to $>0.03 \%$ of GDP, if evaluated relative to GDP. Fig. 4 shows the increased damage caused by tropical cyclones as a fraction of the total costs of climate change. As described earlier, FUND has a range of sub-modules which calculate the economic effects of climate change with respect to individual impact categories ranging from agriculture to human health, and their sum represents the total costs of climate change. Data in Fig. 4 represent the results for the year 2100 in the base case, and the results are shown as ratios to both the gross (i.e. only damage is considered) and net (both benefits and damage are summed) total impacts. While FUND only considers damage with respect to tropical cyclones (since there is no conceivable economic benefit from cyclone intensification), it estimates both damage and the benefits of climate change for some other impact categories (e.g. benefit from increased agricultural productivity due to $\mathrm{CO}_{2}$ fertilization), and this explains why the ratio of enhanced cyclone damage to the total net impact of climate change exhibits a negative value in some cases (i.e. the total net impact of climate change could be beneficial). In Fig. 4, the relative impact is again highest in the Small Island States, and a few other regions (USA, Central America, South Asia) exhibit cyclone damage amounting to over one percent of the total damage by both gross and net measures. However, the gross and net total damage greatly differ (often in sign) in all regions and clear patterns are not discernible.

The other sets of results shown in Table 3 are those of sensitivity runs for different values of parameters. The income elasticities of cyclone damage with regard to direct economic loss and mortality ( $\varepsilon$ and $\eta$ ) increase and decrease according to the standard deviations estimated by Toya \& Skidmore (2007). The higher and lower values of $\delta$ (the parameter representing how much wind speed increases per degree warming) are set to be consistent with the range stated by WMO (2006). The results show that the changes in income elasticity raise the lower estimates by around $10 \%$, whereas the higher and lower $\delta$ bring about larger deviations from the base case, by approximately $30 \%$. Table 3 also lists the results for the case of a high exponent $\gamma$ (8, following Nordhaus 2006). They indicate that the exponent is a very influential parameter for determining the level of damage, showing more than tripled levels of damage in all categories in comparison with the base case. In sum, modulation of parameter levels brings about significant variations in damage estimates, but except for the exponent $\gamma$, variability does not exceed an order of magnitude when assumptions regarding the confidence intervals are consistent with 
the available information. On the other hand, the result of a high exponent $(\gamma)$ run would suggest that our base estimate would be too conservative and that the actual damage increase could be larger by one order of magnitude. As noted earlier, however, setting the exponent as high as 8 is hardly accepted as a convention in the area of storm damage projection. Still, it would suggest that a key topic for future research in this area of study would be a further examination on this parameter.

Our results fall in the range of earlier estimates (Table 4). The results exhibit higher damage costs than those of precedent studies showing increased hurricane impacts on the United States under a doubling of $\mathrm{CO}_{2}$ ( $\$ 0.8$ billion by Cline 1992, $\$ 0.2$ billion by Fankhauser 1995, and $\$ 0.3$ billion by Tol 1995 ; Fankhauser 1995 also estimated the global impact as $\$ 2.7$ billion). The FUND's base case calculates the enhanced direct economic damage in the US with doubled $\mathrm{CO}_{2}$ to be about $\$ 6$ billion $\left(2.5^{\circ} \mathrm{C}\right.$ increase from pre-industrial: for the base run, this level is reached at around the year 2078). It should be noted, however, that the differentials between the FUND results and the other estimates are much reduced if the above figures are converted into the proportion of the total US GDP, which is around $\$ 10$ trillion at present (as opposed to $\$ 34$ trillion computed by FUND for US GDP in 2078). Meanwhile, our estimates are generally lower than the values presented by Downing et al. (1996), who estimated that the

Table 4. Comparison of the present study's estimate of the impact of damage caused by tropical cyclones resulting from climate change with previous assessments. GDP: gross domestic product. IS92a: business-as-usual scenario; IS92d: low population, high energy efficiency scenario. See Downing et al. (1996)

\begin{tabular}{|c|c|c|}
\hline & Billion US\$ & $\%$ of GDP \\
\hline \multicolumn{3}{|l|}{ World } \\
\hline \multicolumn{3}{|l|}{ Present study } \\
\hline $2078^{\mathrm{a}, \mathrm{b}, \mathrm{c}}$ & 13 & 0.0055 \\
\hline $2100^{a}$ & 19 & 0.0057 \\
\hline Downing et al. (1996) & - & $\begin{array}{l}0.1333 \text { (IS92a) } \\
0.0149 \text { (IS92d) }\end{array}$ \\
\hline \multicolumn{3}{|l|}{ USA } \\
\hline \multicolumn{3}{|l|}{ Present study } \\
\hline $2078^{\mathrm{a}, \mathrm{b}, \mathrm{c}}$ & 5.9 & 0.017 \\
\hline $2100^{\mathrm{a}}$ & 8.5 & 0.021 \\
\hline Cline $(1992)^{\mathrm{c}, \mathrm{d}}$ & 0.8 & - \\
\hline Fankhauser $(1995)^{\mathrm{c}, \mathrm{d}}$ & 0.2 & - \\
\hline Tol $(1995)^{\mathrm{c}, \mathrm{d}}$ & 0.3 & - \\
\hline Nordhaus $(2006)^{\mathrm{d}, \mathrm{e}}$ & 8 & 0.064 \\
\hline \multicolumn{3}{|c|}{$\begin{array}{l}\text { a Base run; }{ }^{\mathrm{b}} 2.5^{\circ} \mathrm{C} \text { warming of global average surface tem- } \\
\text { perature } ;{ }^{\mathrm{c}} \text { Doubling } \mathrm{CO}_{2 ;}{ }^{\mathrm{d}} \mathrm{Economic} \text { conditions, e.g. GDP, } \\
\text { are set at the current level } ;{ }^{\mathrm{e}} 2.5^{\circ} \mathrm{C} \text { warming of global aver- } \\
\text { age sea surface temperature }\end{array}$} \\
\hline
\end{tabular}

Table 5. Global marginal costs of $\mathrm{CO}_{2}$ emissions (the present value of all future climate change damage originating from a unit amount of carbon emissions today) in US\$ $\mathrm{t}^{-1} \mathrm{C}$ (the base case, simple sum for the world regions). 'Pure rate of time preference': psychological preference for degree of future discounting relative to the present

\begin{tabular}{|lccc|}
\hline & \multicolumn{3}{c|}{ Pure rate of time preference (\%) } \\
& 0 & 1 & 3 \\
\hline Total & 109 & 9 & -3 \\
Tropical cyclones & 0.34 & 0.09 & 0.03 \\
\hline
\end{tabular}

enhanced effects of natural disasters caused by climate change amount to $0.1333 \%$ of the gross world product under the business-as-usual (IS92a) scenario and $0.0149 \%$ under the low population, high energy efficiency (IS92d) scenario (both medium projections, aggregated effects up to 2100). Also, our estimates of climate change impact on cyclone damage are significantly lower than those of Nordhaus (2006), who concluded that intensified hurricane damage as a result of climate change (i.e. a $2.5^{\circ} \mathrm{C}$ increase in tropical sea surface temperature) would reduce the US GDP by $0.064 \%$ (\$8 billion). Using a simple calculation, Pielke (2007) showed that economic loss caused by tropical cyclones would increase by a factor of 4.6 by 2050 if storm intensity rises by $18 \%$. This figure is significant higher than the range of our estimates (in the base run of FUND, the increase in loss due to cyclones is $\$ 6.7$ billion in 2050 ; thus, a $35 \%$ $(=6.7 / 19)$ increase in loss is expected from the baseline level to the year 2050), and this difference could be explained by the fact that our assumption on cyclone intensity is relatively conservative (increase in intensity $<10 \%$ by 2050 ) and also the responsiveness of damage level to income rise is less than linear in our case in contrast to Pielke's. Finally, the results of FUND show far more conservative projections than Stern's (2006) assessment that the total costs of extreme weather could reach up to $1 \%$ of the world GDP by 2050, although this figure includes extreme weather events other than tropical cyclones.

Table 5 shows the global marginal costs of carbon emissions calculated by FUND for the base case. The results presented are simple sums over the world regions and are not adjusted with equity weights (see Anthoff et al. 2009 for a detailed discussion on that topic with the FUND model). The marginal cost of emissions corresponds to the present value of aggregated future climate change damage originating from a unit amount of carbon emissions today (shadow price of carbon). Note that since the cost of climate change generally becomes larger as time passes by, estimates with a larger pure time preference (with which the future is discounted more strongly) exhibit lower 
marginal costs of $\mathrm{CO}_{2}$ emissions. ${ }^{\mathbf{8}}$ The table shows that in a relative sense, the marginal costs from cyclone damage are negligible relative to the total marginal costs, adding far less than 1 US\$ to the total marginal cost of $\mathrm{CO}_{2}$ emissions $\left(\mathrm{t}^{-1} \mathrm{C}\right)$.

\section{DISCUSSION AND CONCLUSIONS}

We simulated the economic impact of tropical cyclones enhanced by climate change with the integrated assessment model FUND 3.4. The results show that in the base case, the direct economic damage of tropical cyclones ascribed to the effect of climate change amounts to $\$ 19$ billion globally (almost the same level as the baseline [current] global damage of tropical cyclones) in the year 2100, while the ratio to the world GDP is $0.006 \%$. The USA and China account for much of the absolute damage, while the Small Island States incur the largest damage if evaluated as share of the GDP. The results are sensitive to the choice of baseline (e.g. the Katrina effect) and of parameter levels such as that of the wind-speed elasticity of storm damage.

Like other model analyses, this study has limitations, and 3 of them are worth noting. (1) Our computation adopted exogenous savings rates to simulate long-run growth paths under amplifying storms. However, actual investment behavior in the presence of natural disasters is much more nuanced than the way we simulated with the simple model, and more accurate modeling would require endogenous decision functions of investment with representations of risk aversion of economic agents and of maturity of insurance markets (Tol \& Leek 1999). While this effect on the total growth rates could be negligible in large, less storm-prone economies, it could play a significant role for the growth path of smaller, cyclone-ridden economies. (2) The model calculated damage caused by intensifying tropical cyclones as a separate component in the impact module for reasons of analytical clarity and simplicity. This means that the model ignores some combined effects of enhanced cyclones with other factors, most importantly, the coupling effect of sea level rise and stronger cyclones. Sea level rise could increase the vulnerability of coastal regions and thus exacerbate the damage caused by intensified cyclones, which implies that our assessment is rather conservative. Meanwhile, some authors suggest that the primary reason why the cost of cyclone damage

${ }^{8}$ At what level the pure time preference should be set in longterm economic modeling is a hotly debated issue among economists, and a clear consensus has not been reached; yet see, for example, Stern (2006) has increased is because the total monetary value of insured properties in coastal areas has increased and that the damage could be therefore effectively reduced by measures other than climate change mitigation, such as the change in land use (e.g. Pielke et al. 2000). In the present study, we implicitly adopt the assumption that the size of economic activities in coastal regions, the completeness of coastal protection, and also the shifts in land use are all a function of per capita GDP level. However, there is of course a possibility, for example, that low income economies will choose to adopt a very strong policy of cyclone preparedness more than commensurable with their income levels. (3) The incompleteness of knowledge in the science of tropical cyclones, as well as of the climate change phenomena themselves, is always a constraint for studies such as ours. Particularly, we assumed that tropical storms would become more intense, but implicitly kept the frequency and range at their present values. The presence of reliable information about spatial and temporal responsiveness of storm patterns to climate change would improve the robustness of the analysis.

Acknowledgements. Financial support by the US Environmental Protection Agency and the German Research Foundation (the 'Future Ocean' Cluster of Excellence program) is gratefully acknowledged.

\section{LITERATURE CITED}

Acemoglu D, Johnson S, Robinson JA (2001) The colonial origins of comparative development: an empirical investigation. Am Econ Rev 91:1369-1401

Anthoff D, Hepburn C, Tol RSJ (2009) Equity weighting and the marginal damage costs of climate change. Ecol Econ 68:836-849

Cline WR (1992) The economics of global warming. Institute for International Economics, Washington, DC

Deschênes O, Greenstone M (2007) The economic impacts of climate change: evidence from agricultural output and random fluctuations in weather. Am Econ Rev 97:354-385

Downing TE, Eyre N, Greener R, Blackwell D (1996) Projected costs of climate change for two reference scenarios and fossil fuel cycles. Report to the European Commission, ExternE Project, 25 July, 1996. www.mi.uni-hamburg.de/ fileadmin/fnu-files/staff/tol/RM3157.pdf (accessed 9 June 2009)

Easterly W, Levine R (2003) Tropics, germs, and crops: how endowments influence economic development. J Monet Econ 50:3-39

Emanuel K (2003) Tropical cyclones. Annu Rev Earth Planet Sci 31:75-104

Emanuel K (2005) Increasing destructiveness of tropical cyclones over the past 30 years. Nature 436:686-688

- Emanuel K, Sundararajan R, Williams J (2008) Hurricanes and global warming: results from downscaling IPCC AR4 simulations. Bull Am Meteorol Soc 89:347-367

Fankhauser S (1995) Valuing climate change: the economics of the greenhouse. Earthscan, London

Gallup JL, Mellinger A, Sachs JD (2000) Climate, coastal 
proximity, and development. In: Clark GL, Feldman MP, Gertler MS (eds) Oxford handbook of economic geography. Oxford University Press, Oxford, p 169-194

IPCC (2007) Climate Change 2007: the physical science basis. Contribution of Working Group I to the 4th Assessment Report of the Intergovernmental Panel on Climate Change. Cambridge University Press, Cambridge

Jagger TH, Elsner JB, Saunders MA (2008) Forecasting US insured hurricane losses. In: Diaz HF Munrane RJ (eds) Climate extremes and society. Cambridge University Press, Cambridge, p 189-208

Kahn ME (2005) The death toll from natural disasters: the role of income, geography and institutions. Rev Econ Stat 87:271-284

Knutson TR, Sirutis JJ, Garner ST, Vecchi GA, Held IM (2008) Simulated reduction in Atlantic hurricane frequency under twenty-first-century warming conditions. Nat Geosci 1: 359-364

Leggett J, Pepper WJ, Swart RJ (1992) Emission scenarios for the IPCC: an update. In: Houghton JT, Callander BA, Varney SK (eds) Climate change 1992 - the supplementary report to the IPCC Scientific Assessment. Cambridge University Press, Cambridge, p 69-95

Mendelsohn R, Morrison W, Schlesinger ME, Andronova NG (2000) Country-specific market impacts of climate change. Clim Change 45:553-569

Munich Re (2006a) Annual review: natural catastrophes 2005. Munich Re, Munich

Munich Re (2006b) Hurricanes-more intense, more frequent, more expensive: insurance in a time of changing risks. Munich Re, Munich

Nordhaus WD (2006) The economics of hurricanes in the United States. Paper presented at the Annual Meetings of the American Economic Association. NBER Work Pap W12813. http://papers.ssrn.com/sol3/papers.cfm?abstract_ id $=955246$

Nordhaus WD, Boyer J (2000) Warming the world: economic models of global warming. MIT Press, Cambridge, MA

Pielke RA (2007) Future economic damage from tropical cyclones: sensitivities to societal and climate changes. Philos Trans R Soc Ser A 365(1860):1-13

Pielke RA, Klein R, Sarewitz D (2000) Turning the big knob: energy policy as a means to reduce weather impacts. Energy Environ 11:255-274

Porter JR, Semenov MA (2005) Crop responses to climatic variation. Philos Trans R Soc Ser B 360:2021-2035

Rosenzweig C, Tubiello FN, Goldberg R, Millis E, Bloomfield

Editorial responsibility: Balaji Rajagopalan,

Boulder, Colorado, USA
J (2002) Increased crop damage in the US from excess precipitation under climate change. Glob Environ Change 12:197-202

Scheuren JM, le Polain de Waroux O, Below R, Guha-Sapir D, Ponserre S (2008) Annual disaster statistical review: the numbers and trends 2007. CRED, Brussels

Schlenker W, Hanemann WM, Fisher AC (2005) Will US agriculture really benefit from global warming? Accounting for irrigation in the hedonic approach. Am Econ Rev 95: 395-406

Shine KP, Derwent RG, Wuebbles DJ, Morcrette JJ (1990) Radiative forcing of climate. In: Houghton JT, Jenkins GJ, Ephraums JJ (eds) Climate change: the IPCC scientific assessment. Cambridge University Press, Cambridge, $\mathrm{p}$ 41-68

Stern N (2006) The economics of climate change: the Stern review. Cambridge University Press, Cambridge

Swiss Re (2006) Influence of global warming on tropical cyclones, hurricanes and typhoons, October 2006. Swiss Reinsurance, Zurich

Tol RSJ (1995) The damage costs of climate change: toward more comprehensive calculations. Environ Resour Econ 5:353-374

Tol RSJ (1999) The marginal costs of greenhouse gas emissions. Energy J 20:61-81

Tol RSJ (2001) Equitable cost-benefit analysis of climate change policies. Ecol Econ 36:71-85

Tol RSJ (2002a) Estimates of the damage costs of climate change. I. Benchmark estimates. Environ Resour Econ 21: 47-73

Tol RSJ (2002b) Estimates of the damage costs of climate change. II. Dynamic estimates. Environ Resour Econ 21: $135-160$

Tol RSJ (2002c) Welfare specifications and optimal control of climate change: an application of FUND. Energy Econ 24:367-376

Tol RSJ, Leek FPM (1999) Economic analysis of natural disasters. In: Downing TE, Olsthoorn AA, Tol RSJ (eds) Climate, change and risk. Routledge, London, p 308-327

Toya H, Skidmore M (2007) Economic development and the impacts of natural disasters. Econ Lett 94:20-25

> Vecchi GA, Soden BJ (2007) Increased tropical Atlantic wind shear in model projections of global warming. Geophys Res Lett 34:L08702

WMO (World Meteorological Organization)(2006) Summary statement on tropical cyclones and climate change. World Meteorological Organization, Geneva. www.wmo.int/pages/ prog/arep/tmrp/documents/iwtc_summary.pdf

Submitted: October 9, 2008; Accepted: April 3, 2009

Proofs received from author(s): June 5, 2009 